\section{Reading about books on being a junior psychiatrist}

Like most psychiatrists I cannot say precisely when I decided to enter the profession, and in common with most of my colleagues I really did not know what I was letting myself in for. If only I had read a few of the more interesting books about the profession rather than relying on the minimal exposure to the specialty as a medical student! Happily I have now discovered that there are a few interesting books about the junior psychiatrist's experience. Unfortunately some of these are difficult to obtain and are consequently largely unknown by many of their target audience. Here I describe those I have read in order to stimulate awareness and perhaps encourage more additions to the genre.

After travelling throughout the country and investigating many dusty secondhand bookshops, the odd library or two and various obscure websites, I managed to discover five books by or about junior psychiatrists and two books with chapters dedicated to the trainee psychiatrist. Although the relative paucity is surprising, the quality and variety make up for the shortfall.

\section{Books}

The oldest book I found during a trawl through the basement of the Institute of Psychiatry library. Buried deep within the stacks was a book with the politically incorrect title of I Knew 3,000 Lunatics, written by Victor R. Small (1935). It relates the experiences of the author during 6 years he spent as a junior psychiatrist in a state hospital. Interestingly, it does not appear to be particularly dated and many of the incidents and histories are just as apt today. The chapter entitled 'I meet the King', in which the author meets the hospital superintendent, could describe a contemporary meeting of a junior with their consultant/clinical director. I suspect that in 1935 the experience was slightly less formal and angst-inducing than many today. Some chapters (such as 'Dance night') show how occupational therapy has changed over the years but otherwise the book remains a highly readable account of the junior psychiatrist experience some 70 years ago.

The Making of a Psychiatrist by David Viscott (1972) describes, often quite cynically, psychiatric training and relates the author's experiences on acute wards, in the out-patient department, in child and adolescent psychiatry, in a forensic medicine institute and eventually in private practice. He details successes, failures, his opinions about his fellow trainees and senior colleagues and even his own brief experience as a patient undergoing psychoanalysis. He ultimately seems dismayed by the system and the process and admits at the beginning of the book that his views may upset other psychiatrists. However, of the five books reviewed here, this one stands out for its frank comments on an admittedly unusual profession and its seemingly bizarre training and traditions.

Mark Warren's The Making of a Modern Psychiatrist, published in 1986, also describes the author's experiences during higher training but seems to be more about his turbulent relationship with his wife rather than specifically about psychiatry. The titles of the chapters ('fantasy, denial, fear, acting out', etc.) suggest a preoccupation with psychotherapy. However, there are some interesting anecdotes about the life of a trainee psychiatrist; it is just a pity that the book seems to be an exercise in personal catharsis.

In a House of Dreams and Glass: Becoming a Psychiatrist by Robert Klitzman (1995) is similar in style to The Making of a Psychiatrist but is far less cynical and angry. It describes the author's experience over 3 years of residency training, including 'on the other side of the couch' as a patient undergoing psychotherapy. The book ends with an interesting series of reflections and is overall a readable and important account of the pitfalls and paradoxes of training, which should be read by all psychiatrists at some point in their careers.

An additional work that should be mandatory is a dark and apparently fictional account of a trainee psychiatrist's experiences in the eponymous hospital of the book's title, Mount Misery (Shem, 1997). Shem also wrote the brilliant House of God, which is about the surreal experience of being a medical intern. Mount Misery reads as though it were written in hindsight and overall appears to be a not particularly thinly veiled attack on psychotherapy in general and psychotherapists in particular. However, it is an interesting read and many of the grotesque caricatures will be recognised, at least in part, by a proportion of current trainees. Unfortunately, it is not as good as the author's first book, which remains a classic and is well worth reading.

\section{Book chapters}

Two more books written by British doctors have chapters or contributions detailing experiences of junior psychiatrists. The first, entitled Fool or Physician The Memoirs of a Sceptical Doctor, is by Anthony Daniels (1987) who returned to the UK from South Africa to spend 3 years training as a psychiatrist in London. He has some interesting tales to tell about his experiences, including some candid opinions about his fellow psychiatrists.

The sink or swim mentality that is occasionally found in psychiatric training is brilliantly described in Michael Foxton's dark collection of anecdotes entitled Bedside Stories: Confessions of a Junior Doctor, which was published in 2003. In this highly readable book the author describes his house jobs, his stint in accident and emergency departments and finally some of his time in psychiatry. In a series of short articles he muses on various topical concerns, including being eft alone in a room with an angry patient and suffering through a mental health tribunal. This and more will instantly be recognisable to the struggling trainee, who really should read this book as well as the ones described above, so that they know they are not alone, that we all go through this and, yes, we can and do survive the experience!

DANIELS, A. (1987) Fool or Physician: The Memoirs ofa Sceptical Doctor. London: John Murray.

FOXTON, M. (2003) Bedside Stories: Confessions of a Junior Doctor. London: Guardian Books.

KLITZMAN, R. (1995) In a House of Dreams and Glass: Becoming a Psychiatrist. New York: Ivy Books.

SHEM, S. (1997) Mount Misery. New York: Ivy Books.

SMALL, V. R. (1935) I Knew 3,000 Lunatics. London: Rich \& Cowan.

VISCOTT, D. S. (1972) The Making of a Psychiatrist. Greenwich, CT: Fawcett Publications.

WARREN, M. (1986) The Making of a Modern Psychiatrist. Garden City, NW: Doubleday.

Russell Foster HIV Mental HealthTeam, First Floor, Outpatients, Maudsley Hospital, Denmark Hill, London SE5 8AZ, e-mail: r.foster@iop.kcl.ac.uk 